\title{
Truth-Revealing Mechanisms for Courts
}

by

\author{
Robert Cooter ${ }^{*}$ and Winand Emons ${ }^{* *}$
}

January 2000

\begin{abstract}
In trials witnesses often slant their testimony in order to advance their own interests. To obtain truthful testimony, the law relies on cross-examination under threat of prosecution for perjury. We show that perjury law is an imperfect truth-revealing mechanism. More importantly, we develop a perfect truth-revealing mechanism. Under this mechanism the witness is sanctioned if a court eventually finds that the testimony was incorrect; the court need not determine that testimony was dishonest. We explain how truth-revealing mechanisms could combat distortions of observations by factual witnesses and exaggerations by experts, including "junk science."

Journal of Economic Literature Classification Numbers: D82, K41, K42.

Keywords: litigation process, truth-revealing multi-dimensional mechanism, perjury rule.

\footnotetext{
*School of Law (Boalt Hall), University of California Berkeley, CA 94720, USA, rdc@law.berkeley.edu, http://www.law.berkeley.edu/faculty/CooterR/

${ }^{* * *}$ Department of Economics, University of Bern, Gesellschaftsstrasse 49, CH-3012 Bern, Switzerland, winand.emons@ vwi.unibe.ch, http://www-vwi.unibe.ch/theory/emons03.htm.

We thank Rafael Gely, Hans Peter Grüner, Martin Hellwig, Lewis Kornhauser, Benny Moldovanu, Eric Rasmusen, Urs Schweizer, and Matt Spitzer for helpful comments.
} 


\section{Introduction}

In deciding legal disputes, courts must rely on observers to report facts and experts to provide opinions. Witnesses, however, often gain from providing false testimony. Many witnesses have a material interest in the case. For example, the plaintiff and defendant have a material interest in the judgment, and an expert has an interest in future employment as a witness. ${ }^{1}$ The interest of the witness in the case provides an incentive to slant testimony.

To obtain the full truth from self-interested witnesses, the legal process needs to provide incentives that offset the gain from slanted testimony. Deterrence requires a rationally self-interested witness to pay an expected price for slanted testimony greater or equal to the expected gain.

The law relies on cross-examination under the threat of prosecution for perjury to deter false testimony. Cross-examination probes the quality of testimony by the witness, searching for internal inconsistencies or contradictions with testimony by other witnesses. In a criminal trial for perjury, the plaintiff must prove that the defendant lied (told a falsehood knowingly) or, possibly, that the defendant recklessly disregarded the truth. ${ }^{2}$ If the law allows civil liability for false testimony, the plaintiff in a civil case must prove the relevant form of fault by the defendant. In either case, the plaintiff must prove that the defendant violated a legal standard when testifying.

Establishing guilt or liability often requires more information than anyone can prove in court, so perjury trials or civil trials arising from perjury are rare. In practice, a

\footnotetext{
${ }^{1}$ For the rapid growth of economists acting as expert witnesses see Posner (1999), Thornton and Ward (1999), and Mandel (1999). This form of consulting is now designated "forensic economics". Several associations such as, e.g., the National Association of Forensic Economics (NAFE) as well as a couple of journals like, e.g., the Journal of Forensic Economics have emerged due to this boom in the demand for economists as experts.

${ }^{2}$ According to the Model Penal Code, perjury requires testimony in court under oath that is misleading and material. In addition, perjury requires knowledge that the assertion was false when made, or, possibly, reckless disregard for the truth. False testimony in an American court cannot support a civil suit for damages, so a victim of slander or libel in court has no legal remedy. For a more elaborate discussion of the legal institutions, see Cooter and Emons (2000).
} 
skillful witness can slant testimony without fear that the plaintiff in a suit can prove that the witness violated a legal standard. Moreover, as we show formally, even when all this information is available, perjury rules are not perfect truth-revealing.

This paper applies the theory of mechanism design to the courtroom. We derive a system of sanctions, which is perfectly truth-revealing. We replace the fault-based perjury rule with a rule of strict liability. Under our rule of strict liability, the witness pays a sanction for testimony that proves inaccurate, regardless of whether inaccuracy was the witness's fault. Replacing a fault-based rule with strict liability reduces the information needed by the plaintiff to impose the sanction. In principle, a rule of strict liability can deter distortions by factual witnesses and exaggerations by experts, including "junk science.",

To further motivate our analysis, consider the following four examples of testimony by witnesses to which our model applies:

Example 1: A suit between two motorists over an automobile accident turns on who was at fault. A pedestrian, who is neutral between the parties, observed the accident. The pedestrian testifies on the question, "Was the stoplight red?"

Example 2: A woman maintains a sexual liaison with a handsome poor man and an ugly rich man. When a child is born, the mother needs to establish the father's identity to win a paternity suit by testifying on the question, "Who is the child's father?"

Example 3: In a suit for damages, the defendant considers whether to argue that he is not liable because he did nothing wrong, or to argue that he is liable and the damages are slight. The second argument undermines the first argument, so the defense attorney does not want to make both arguments. The defense attorney's choice of an argument depends upon how the defendant's expert answers the question, "Did the defendant do wrong?" Example 4: A rich man and a poor man go hunting. The two hunters shoot at a bird and one of them injures a third person. In a suit for damages, the judge has an interest in finding someone liable, preferably the rich hunter. Following

\footnotetext{
${ }^{3}$ Martha Nussbaum's testimony in Romer v. Evans seems to be an example of expert perjury. She seems to have misleadingly cited the long superseded 1897 edition of a Greek-English lexicon listing no pejorative connotation of the Greek word tolmêma whereas in the later 1940 edition, which she normally cites in her academic work, "shameless act" is included as a possible translation of tolmêma. See Lingua Franca, Sept/Oct. 1996, http://www.linguafranca.com/9609/stand.html.
} 
the practice in many civil law countries, the judge chooses a ballistic expert to testify on the question, "Which gun fired the bullet that struck the plaintiff?"

In Example 1, the pedestrian who witnesses the accident is neutral in the sense that the decision of the court does not affect her material interests. In Example 2, the mother testifying about her child's paternity has a direct material interest in the case. In Example 3, a party to the case pays an expert witness, as is the usual practice in the "adversarial" systems of the common law countries. By advancing the interests of the party retaining her, an expert witness increases her prospects for employment in subsequent cases. In Example 4, the court selects an expert witness, as is the usual practice in the "inquisitorial" systems of the civil law countries. The judge might have an interest in the case because he wants to resolve it quickly with least effort, please his superiors who can promote him, obtain a bribe, or he is a friend of the plaintiff. ${ }^{4}$ By advancing the interests of the judge in Example 4, the expert witness increases her prospects of being hired by courts in subsequent cases.

All of our witnesses observe a fact that is relatively good or relatively bad for the defendant or plaintiff. The witness is either pretty certain or rather uncertain about the observation's accuracy. In terms of Example 1, the pedestrian may have observed that the stoplight was red, but she may be rather uncertain because the sun blinded her. In technical language, a witness receives a signal that is better or worse with high or low precision. When testifying in court, a witness reports on the signal's content (better/worse) and precision (high/low). An honest witness reports truthfully about content, and a dishonest witness reports falsely about content. A candid witness reports accurately about precision, and a misleading witness reports inaccurately about precision.

\footnotetext{
${ }^{4}$ Usman (1999) endogenously determines the level of verifiability assuming a judge who values correct rulings but dislikes effort.
} 
The court uses the available evidence, including the testimony of witnesses, to decide the case. ${ }^{5}$ After a witness testifies, subsequent events may prove that the testimony was right or wrong. To illustrate by Example 1, after the pedestrian testifies that the stoplight was red, someone may discover a photograph proving conclusively that the stoplight was green. In Example 2, the mother may testify that the poor man was the father and, after the trial, subsequent developments in biology may result in a proof that she was right.

Our model stylizes these facts. We assume that, after the witness testifies, the court or similar body subsequently learns with positive probability whether the witness was wrong or right. In our model, a truth-revealing mechanism uses the testimony of the witness and any subsequent findings by the court to possibly sanction the witness.

A perfect truth-revealing mechanism induces honest and candid testimony in all circumstances. ${ }^{6}$ Our mechanism has a straightforward interpretation. A witness may gain from dishonest or misleading testimony. Against this gain, the witness must balance the probability and magnitude of a sanction. A perfect truth-revealing mechanism imposes an expected sanction equal to the gain from dishonesty or disingenuousness.

To illustrate, consider the mother in Example 2. Assume she is certain that the poor man is the father. She will, however, enjoy a larger court award by asserting falsely that she believes with certainty that the rich man is the father. Perhaps officials will eventually discover the truth through advances in biology. By definition, the expected sanction equals the probability that such events will trigger a sanction multiplied by the sanction's magnitude. With our perfect truth-revealing mechanism, the expected sanction exactly equals the mother's gain from a false report.

\footnotetext{
${ }^{5}$ An episode in the 1935 Howard Hawks' movie Barbary Coast nicely fits our model: As the defendant is being marched off to the gallows, the trial occurs. The de facto judge asks two questions: "Did you see the defendant shoot Bill?" On this being answered affirmatively, the second question is: "Are you sure". That too being affirmative, the defendant is hanged. (footnote needs to be double checked)

${ }^{6}$ Our aim throughout the paper is to reveal the truth. From a societal point of view there may be cases where lies are better than the truth, e.g., if somebody lies to protect a lady's honor, or if a government official lies about a foreign policy event to protect ongoing dealings.
} 
As another illustration, consider the ballistic expert in Example 4. Assume her tests indicate that the rich hunter fired the fatal bullet, but she is uncertain about these tests. To promote her future business, the expert can help the judge by testifying falsely that she is certain that the rich hunter fired the fatal bullet. Doing so, however, the expert runs the risk that someone will subsequently present irrefutable proof that the poor hunter fired the fatal bullet. With our perfect truth-revealing mechanism, the expected sanction increases when the expert asserts her conclusion with certainty rather than uncertainty, and the increase exactly equals the gain to the expert from more future business.

The sanctions in the perfect truth-revealing mechanism can be interpreted as bond forfeited by the witness in the event that evidence disconfirms her testimony. ${ }^{7}$ To illustrate by Example 3, assume the witness reports that the defendant did not do wrong and that she is uncertain. The court and the plaintiff's counsel may suspect that the witness actually observed with uncertainty that the defendant did wrong. The court or the plaintiff's counsel challenges the witness to bond her testimony. To retain credibility, the witness has to post bond.

What is the minimum bond inducing honest and candid testimony? The expected sanction must equal the witness's gain from dishonest and/or misleading testimony. In principle, the court and plaintiff's counsel can compute the minimal sanction from the witness's gain and the probability of disconfirming evidence. Thus the counsel and court requires the witness who testifies "no wrong and imprecise" to post a truth-bond at least equal to the minimal sanction in order to establish credibility.

To illustrate by Example 2, assume the ballistic expert testifies that the evidence indicates that the rich hunter fired the fatal shot, although she cannot be certain. The defendant's attorney, however, suspects that the witness is dishonest. He may challenge the witness to establish her credibility by bonding her assertion. "Would you bond the proposition that 3 out of 4 ballistic experts who examined the same evidence as you

\footnotetext{
${ }^{7}$ See Cooter and Emons (2000) for an elaborate discussion on how truth-bonding might work in practice.
} 
would agree with your conclusion?" The optimal bond equals the increase in the payoff to the ballistic expert from testifying "rich hunter" rather than "poor hunter," divided by the probability that at least 2 out of 4 ballistic experts would disagree with her.

Let us now turn to a limitation of our truth-revealing mechanism. In all of our examples the witness benefits more from testifying that she observed "better" rather than "worse" given the precision. ${ }^{8}$ She also benefits more from testifying that she is "certain" rather than "uncertain" given the content. Accordingly, payoffs increase whenever the report's content and certainty improve. This is analogous to a portfolio of stocks becoming more valuable whenever the mean increases and/or the variance decreases.

To illustrate, in Example 2 the mother gains most from testifying with certainty that the rich man is the father. Next, she gains from testifying with certainty that the poor man is the father. The worst possibilities occur when she cannot testify with certainty about the father's identity, in which case she may not win in court.

Example 3 also fits this pattern of reasoning. The defendant's expert benefits the defendant most (and, hence, benefits herself most) by asserting that the defendant certainly did nothing wrong. Next, the expert benefits the defendant by asserting that the defendant did something wrong and the damages are certainly small. The expert benefits the defendant least by asserting that she is uncertain whether the defendant did right or wrong. This pattern of benefits, which fits the conception of the defense in Texaco $v$. Pennzoil, ${ }^{9}$ applies whenever the defendant prefers to take a stand on only one issue.

Our mechanism no longer works in scenarios where the witness benefits from being uncertain rather than certain. To illustrate by an example: If an alleged monopolist's expert finds out that the company has indeed a high market share, the expert (and the monopolist) benefits from testifying to this fact with uncertainty rather than certainty. Such a pattern of payoffs violates a monotonicity requirement necessary

\footnotetext{
${ }^{8}$ For purposes of our analysis, the opposite is also acceptable, because "better" and "worse" are arbitrary.

9 Texaco's lawyer refused to offer expert testimony on damages on the theory that doing so would undermine the confidence of the court that Texaco was not a fault. This proved a disastrous mistake because Pennzoil claimed damages equal to the sale value of the oil field, rather than the expected profits that the oil field would yield. See, e.g., Petzinger (1999).
} 
for the existence of a perfect truth-revealing mechanism sanctioning only wrong testimony. More possibilities to sanction are then necessary to induce truth-telling. We sketch such a mechanism, which also sanctions right testimony. ${ }^{10}$

Finally, we analyze the fault-based perjury rule in our set-up. Under the perjury rule if the testimony were wrong, the court must use this information to compute the probability that the witness was dishonest. If this probability exceeds the legal standard, the court imposes the sanction for perjury. As we show formally, these Bayesian inferences are fairly difficult to make and require a lot of information. This fact provides one reason why perjury prosecutions are so rare.

Next we show that under perjury law a neutral witness will never report a high precision signal. Since a court is more likely to find perjury when testimony was given with certainty rather than uncertainty, a neutral witness minimizes the probability of being sanctioned for perjury by understating her certainty. Finally, since a simple perjury rule does not adjust the sanction to the probability of detecting and prosecuting the perjury, it lacks the sophistication, which is necessary to induce an interest witness to tell the truth. Because of these limitations, a perjury rule is, therefore, an imperfect truthrevealing mechanism.

The remainder of the paper is organized as follows. In the next section we describe our basic framework. In section 3 we analyze the witness's incentives. In section 4 we derive the perfect truth-revealing mechanism. In section 5 we discuss the perjury rule. The last section concludes. Proofs are relegated to the Appendix.

\section{The Model}

A court's decision in a case depends on the outcome of a random event. This random variable $\tilde{X}$ can take the two realizations $X=A$ and $X=B$. To illustrate, a drug may have

\footnotetext{
${ }^{10}$ In a subsequent paper we hope to explore this problem further and show that within the class of mechanisms sanctioning only wrong testimony, our mechanism is second-best optimal when no perfect truth-revealing mechanism exists.
} 
two side-effects, one $(B)$ somewhat worse than the other $(A)$. Or " $B$ " might mean, "the shot was fired by the poor hunter" and " $A$ " "the rich hunter fired the fatal shot." The court has some information about the likelihood of the two events which we denote by $\operatorname{Prob}(X=B):=\operatorname{Prob}(B)$ and $\operatorname{Prob}(X=A):=\operatorname{Prob}(A)=1-\operatorname{Prob}(B) .{ }^{11}$

The defendant can base his defense on either $A$ or $B$. His case is somewhat stronger for $A$ than for $B$. A good defense for $A$ is, however, a pretty bad one for $B$ and vice versa. The defendant is, therefore, interested in obtaining as much information as possible about which state of the world will materialize. If the two states are equally likely, he prefers, of course, $A$.

Consider, e.g., the side effects caused by the drug. If both possibilities are equally likely, the drug company has to argue that it took appropriate measures against both side-effects. If the defendant can convince the court that one of the two effects occurred rather than the other, he can focus his defense rather than fighting on two fronts like Germany in World Wars One and Two.

Formally, we define the indicator variable $U(A)=1$ and $U(B)=0$. The defendant's utility function is then given as

$$
V=E U(\tilde{X})-\alpha \operatorname{Var} U(\tilde{X})=\operatorname{Prob}(A)-\alpha \operatorname{Prob}(A) \operatorname{Prob}(B)
$$

where $E$ stands for the expected value, Var for the variance of the indicator variable, and $\alpha$ measures the (dis-) taste of the associated risk. We assume $\alpha$ to be sufficiently large which we will make precise below.

A witness observes a fact with an attached probability, which we call a signal, that is relevant to the court's decision. ${ }^{12}$ To illustrate concretely, the witness observes a medical fact and infers a definite probability about the occurrence of the side-effects. Or the witness runs some tests and infers a definite probability about which gun fired the fatal shot. In notation, the witness has observed a signal $(Y, P), Y \in\{A, B\}, P \in\{L, H\}$,

\footnotetext{
${ }^{11}$ If the court has no further information, by the principle of insufficient reason $\operatorname{Prob}(B)=\operatorname{Prob}(A)=1 / 2$.

${ }^{12}$ As in Shin (1999) we treat the information collection process as exogenous in order to focus on the incentives to disclose the evidence. In Dewatripont and Tirole (1999) information gathering is costly; their focus is on the incentive to gather information.
} 
meaning that the state of the world $Y$ will occur with probability $P$. The signal $(B, H)$, for example, means that the state $B$ will occur with probability $H$, which of course implies that the state $A$ occurs with probability $(1-H)$. Similarly, the signal $(A, L)$ means that the state $A$ occurs with probability $L$, etc.

First of all we assume that all four signals reduce uncertainty; furthermore, it is convenient to define $H$ and $L$ so that one is more precise than the other in the sense of conveying more information, or formally, $1>H>L>\max [\operatorname{Prob}(B) ; \operatorname{Prob}(A)] \geq 1 / 2$. By this condition, a signal $(B, L)$ or $(A, L)$ is low precision, and a signal $(B, H)$ or $(A, H)$ is high precision. We can now make precise the defendant's distaste of risk, i.e., we assume $\alpha>(L-(1-H)) /(L(1-L)-H(1-H))$. If $\alpha$ satisfies this condition, the defendant prefers $(A, H)$ to $(B, H)$ to $(A, L)$ to $(B, L)$ to no signal at all. ${ }^{13}$

As an example consider tossing two dice. The state $A$ corresponds to the sum of the two dice exceeding 7, while $B$ occurs when the sum is 7 or less. Accordingly, $\operatorname{Prob}(A)=5 / 12$ and $\operatorname{Prob}(B)=7 / 12$.

After the two dice are rolled, the witness observes something about the number on one of them. The witness observes either one of the two high precision signals $\{5,6\}$ and $\{1,2,3,4\}$. The information that the first die is either 5 or 6 translates into the signal that the good state occurs with probability $3 / 4$, i.e., $(A, 3 / 4)$ and the information that the first die is less than 5 corresponds to the signal $(B, 3 / 4)$. Alternatively, the witness observes one of the two low precision signals $\{4,5,6\}$ corresponding to $(A, 2 / 3)$ and $\{1,2,3,4,5\}$ corresponding to $(B, 2 / 3)$.

The witness testifies in court on her private information. She announces a state of the world and the probability with which this state will occur. ${ }^{14}$ To avoid confusion, we use small letters for her reported values. Formally, the witness announces $(y, p)$,

\footnotetext{
${ }^{13}$ Our analysis easily carries over to the case where the defendant's preferences are $(A, H) \succ(A, L) \succ$ $(B, H) \succ(B, L)$. In Proposition 4 we show that truth-revelation is impossible if we sanction only wrong testimony when montonicity in the precision is violated.

${ }^{14}$ We thus confine our attention to direct revelation mechanisms. By the revelation principle, this implies no loss of generality. See, e.g., Myerson (1985).
} 
$y \in\{a, b\}$ and $p \in\{l, h\}$. We will use the following semantics: If $y=Y$, testimony is honest; otherwise, testimony is dishonest. If $p=P$, testimony is candid; otherwise, testimony is misleading. Our aim is, quite naturally, to get an honest and candid testimony. ${ }^{15}$

Depending on her reported values, the witness receives a remuneration (wage) $w(y, p) \geq 0$ from a third party. Taking future consequences into account, remuneration is higher when the testimony is more favorable to the party for whom the testimony is given. In a trial, testimony that favors one party disfavors the other party. Consequently, we will view testimony from the viewpoint of one party, we will take the defendant, and scale values accordingly. In our setup the defendant prefers high $(h)$ to low ( $l$ ) precision signals and better $(a)$ to worse (b) news. Consequently, $w(a, h) \geq w(b, h) \geq w(a, l) \geq w(b, l){ }^{16}$

The wage depends upon the legal and contractual status of the witness. An interested witness receives a wage for testimony that increases with the strength of her testimony. Formally, for an interested witness all three of the above wage inequalities are strict. Typically, an interested witness is a party to the suit or an expert paid by a party to the suit. Under US rules, expert witnesses are interested. A neutral witness receives a constant wage for testifying, meaning that the equality holds in all of the above weak inequalities. If this constant wage is zero, we will call the witness disinterested. Under European rules, expert witnesses are more often neutral. Under European and American rules, witnesses to the facts are typically unpaid for testimony, so they are neutral unless connected to the plaintiff or defendant.

After the witness has testified, further developments in the trial may reflect upon the accuracy of the witness's testimony. We stylize this fact by assuming that the court

\footnotetext{
${ }^{15}$ In our set-up the witness can lie, i.e., report false information. There is a related literature comparing the adversarial (partisan) procedure of the Anglo-Saxon law in which partisan advocates present their cases to an impartial jury with the inquisitorial procedures of Roman-Germanic countries in which judges take an active role in investigating a case (Dewatripont and Tirole (1999) and Shin (1999)). In these papers a party can conceal information but cannot report false information. Shin (1999) justifies the assumption of no false evidence (all reported information is verifiable) with the effectiveness of perjury rules. Our results on perjury rules tend to qualify this assumption.
} 
observes the true state of the world after the trial's end. ${ }^{17}$ We will say the testimony is right if $X=y$; otherwise, the testimony is wrong. Conditional on the relationship between the testimony and the court's observation, the witness can be rewarded or sanctioned. Formally, we denote a sanction/reward by $S(X, y, p)$ where $S>0$ is a sanction and $S<0$ a reward. We want to derive mechanisms working with minimal sanctions and rewards. Therefore, we set the sanction equal to zero whenever the testimony is right, i.e., $S(B, b, l)=S(A, a, l)=S(B, b, h)=S(A, a, h)=0$.

The witness's expected payoff equals her wage minus the expected sanction. Formally, the payoff is given as $w(y, p)-E(S(\tilde{X}, y, p) \mid Y, P)$ where $E(S(\tilde{X}, y, p) \mid Y, P)$ stands for the expected sanction given her reported testimony $(y, p)$ and the true information $(Y, P)$. She chooses her reported testimony $(y, p)$ so as to maximize her expected payoff.

\section{The Incentive Constraints}

We want to derive a system of sanctions that induces the witness to be honest and candid. We call such a mechanism perfect truth-revealing. This means that reporting the true signal must generate at least as much payoff as announcing any other signal. Formally, this requirement means

$$
\begin{gathered}
w(Y, P)-E(S(\tilde{X}, Y, P) \mid Y, P) \geq w(y, p)-E(S(\tilde{X}, y, p) \mid Y, P) \\
\forall(y, p) \in\{b, a\} \times\{l, h\}, \quad \forall(Y, P) \in\{B, A\} \times\{L, H\} .
\end{gathered}
$$

Consider, for example, the case in which the true signal is $(Y, P)=(B, L)$. Here one of our tasks is to guarantee that announcing $(y, p)=(b, l)$ is at least as good as reporting

\footnotetext{
${ }^{16}$ Note that we do not further analyze the relationship between the defendant and the witness. We have specified the defendant's preferences only to motivate the witness's wage schedule.

${ }^{17}$ Since everybody in our model is risk neutral, it is straightforward to extend the analysis to the case in which the court observes the true state only with a probability $\gamma<1$. Then all the sanctions in the perfect truth-revealing mechanism have to be multiplied by $1 / \gamma$. Note that we could work with any imperfect signal of the witness's observation $(Y, P)$. To save on notation we have chosen the true state of the world.
} 
$(a, l)$. Formally, this means $w(b, l)-(1-L) S(A, b, l) \geq w(a, l)-L S(B, a, l) .{ }^{18}$ If the witness tells the truth, she receives the wage $w(b, l)$. With probability $(1-L)$ the state $A$ materializes and the witness has to pay the sanction $S(A, b, l)$. If, in contrast, she reports $(a, l)$, she receives the (higher) wage $w(a, l)$. Now the sanction is $S(B, a, l)$, triggered by the state $B$ which occurs with the (high) probability $L$ if $(B, L)$ is the true signal. Similarly, if the true state is $(Y, P)=(B, L)$, we must guarantee that the message $(y, p)=(b, l)$ is at least as good as the reports $(b, h)$ and $(a, h)$.

Analogous incentive constraints hold for the other 3 signals so that overall we end up with 12 incentive constraints. After some algebraic manipulation and rearranging we have the following system of 6 weak inequalities.

$$
\begin{aligned}
& (1-L) S(B, a, h)-(1-L) S(B, a, l) \geq w(a, h)-w(a, l) \geq(1-H) S(B, a, h)-(1-H) S(B, a, l), \\
& (1-L) S(A, b, h)-(1-L) S(A, b, l) \geq w(b, h)-w(b, l) \geq(1-H) S(A, b, h)-(1-H) S(A, b, l), \\
& L S(B, a, l)-(1-L) S(A, b, l) \geq w(a, l)-w(b, l) \geq(1-L) S(B, a, l)-L S(A, b, l), \\
& H S(B, a, h)-(1-H) S(A, b, h) \geq w(a, h)-w(b, h) \geq(1-H) S(B, a, h)-H S(A, b, h), \\
& L S(B, a, h)-(1-L) S(A, b, l) \geq w(a, h)-w(b, l) \geq(1-H) S(B, a, h)-H S(A, b, l), \\
& L S(B, a, h)-(1-L) S(A, b, l) \geq w(a, l)-w(b, h) \geq(1-H) S(B, a, h)-H S(A, b, l) ;
\end{aligned}
$$

call the first inequality in such a chain (a) and the second one (b).

Before deriving the perfect truth-revealing mechanism in detail, we can already state a preliminary result, namely that truth-revealing mechanisms differ for interested and neutral witnesses. For a neutral witness, sanctions must be constant, whereas for an interested witness the sanctions increase with the strength of the testimony.

Proposition 1: Perfect truth-revealing sanctions for interested witnesses satisfy $S(A, b, l)$ $<S(A, b, h)$ and $S(B, a, l)<S(B, a, h)$. If the witness is neutral, $S(A, b, l)=S(A, b, h)=$ $S(B, a, l)=S(B, a, h)$.

The intuition for this result is straightforward. An interested witness's wage increases with the strength of the testimony, being maximal for the reported value $(a, h)$.

\footnotetext{
${ }^{18}$ Recall that we set the sanction to zero whenever the testimony is right, so $S(B, b l)=S(A, a, l)=0$.
} 
If the sanctions were, say, constant, an interested witness would always report $(a, h)$. To compensate for the increasing wage schedule, sanctions must increase with the strength of the testimony. Conversely, if the witness is neutral, the wage schedule provides no incentives not to tell the truth. In order not to distort the wage schedule's proper incentives, the sanctions must be neutral too.

\section{The perfect truth-revealing Mechanism}

Let us now determine the truth-revealing mechanism. We focus on mechanisms employing minimal sanctions/rewards. This means first that we set as many sanctions as possible to zero; second, we set those sanctions, which need to be positive, to the minimal values still providing proper incentives. We make the sanctions as low as possible in order to minimize the monetary strain on the witness. See also the following discussion on individual rationality in Proposition 3. The reason why we do not work with rewards is twofold. First, we want to keep the cost of the judicial system low and rewards are costly. A second problem arises if rewards become so high that before having observed the signal the witness knows she will receive an expected reward. Then agents without any knowledge of the case may try to be called upon as witness simply to cash in on the expected reward. ${ }^{19}$

Proposition 2: The perfect truth-revealing mechanism using minimal sanctions/rewards is given by

$S^{*}(X, y, p)= \begin{cases}(w(a, h)-w(a, l)) /(1-L)+(w(a, l)-w(b, l)) / L, & \text { if } X=B, y=a, p=h ; \\ (w(b, h)-w(b, l)) /(1-L), & \text { if } X=A, y=b, p=h ; \\ (w(a, l)-w(b, l)) / L, & \text { if } X=B, y=a, p=l ; \\ 0, & \text { otherwise. }\end{cases}$

The truth-revealing mechanism obviously reflects Proposition 1. If the witness is neutral, all sanctions are zero. If the witness is interested, sanctions increase with the strength of the testimony.

\footnotetext{
${ }^{19}$ See Emons and Sobel (1991) for a more elaborate discussion of the problems generated by expected rewards.
} 
The sanctions are constructed as follows. When the witness works out, for instance, whether to report the true weak or a false strong signal, she compares the increase in the wage with the increase in the expected sanction. Accordingly, all we have to do is to ensure that the increase in the expected sanction is at least as great as the increase in the wage. This task is somewhat tedious due to the stochastic nature of our problem; sanctions appear in several incentive constraints at the same time. This generates several lower bounds for certain sanctions, and of these we have to take the maximum. With this type of construction, for a certain deviation the witness is just indifferent while for other deviations the incentives are strict. Finally, we have to check that we did not overdo it, i.e., set the sanctions so high that they distort the witness' incentives elsewhere.

After all this technical parlance it seems a good idea to illustrate the truth-revealing mechanism using the dice example. Recall that $L=2 / 3$ and $H=3 / 4$. Let $w(b, l)=0$, $w(a, l)=6, w(b, h)=8$, and $w(a, h)=10$. Then $S(A, b, l)=0, S(A, b, h)=24, S(B, a, l)=9$, and $S(B, a, h)=21$.

If the witness has observed, for example, $(A, L)$, expected sanctions for the possible reports are given by Figure 1. Given the true report $(a, l)$, the "marginal" expected sanctions are greater or equal the "marginal" wages, making any deviation from reporting the true signal unattractive.

\section{Figure 1}

\begin{tabular}{|l|l|l|l|l|}
\hline \multicolumn{4}{|l|}{ Perfect Truth-Revealing Mechanism for the signal $(A, L)$} \\
\hline report & $(a, h)$ & $(b, h)$ & $(a, l)$ & $(b, l)$ \\
\hline Wage to witness & 10 & 8 & 6 & 0 \\
\hline $\begin{array}{l}\text { Expected sanction given the } \\
\text { signal }(A, L)\end{array}$ & 7 & 16 & 3 & 0 \\
\hline Net payoff & 3 & -8 & 3 & 0 \\
\hline
\end{tabular}


Here the surprising feature is that the highest sanction is imposed when the witness has reported $(b, h)$ and $A$ materializes. This result follows immediately from (2a). Reporting $(b, h)$ rather than $(b, l)$ increases the wage by a steep 8 . This increase has to be compensated by $S(A, b, h)$ which is imposed only with the (low) probability $(1-L)=1 / 3$. We have chosen the example deliberately such that the monotonicity of the wage scheme is not entirely reflected in the sanctions. ${ }^{20}$ Wages are monotone increasing in the strength of the testimony, but sanctions are not. The highest sanction is imposed for the second highest testimony. Note that such non-monotone incentive schemes are the rule rather than the exception. In the principal-agent problem, for example, the agent's remuneration is typically not monotone in the outcome. See, e.g., Grossman and Hart (1983).

Another unpleasant feature of truth-revealing mechanisms is that agents often do worse if they participate in the mechanism than if the do not participate. In mechanism design jargon, participation in an incentive scheme with this feature is not individually rational. Agents do better if they stay out of the incentive scheme than if they take part: they must be forced to participate. ${ }^{21}$ Translated into our problem, (interim) individual rationality requires that the witness's expected payoff is non-negative whatever signal she received. ${ }^{22}$ To put it differently, expected sanctions may not exceed the wage, or formally

$$
w(Y, P)-E(S(\tilde{X}, Y, P) \mid Y, P) \geq 0 \quad \forall(Y, P) \in\{B, A\} \times\{L, H\} .
$$

Fortunately, our mechanism is well behaved.

Proposition 3: The mechanism $S^{*}(X, y, p)$ defined in Proposition 2 is individually rational.

This result, which follows more or less immediately from our construction has the implication that the witness, whatever signal she receives, need not be forced to testify in

\footnotetext{
${ }^{20}$ Note that we are talking now about actual rather than expected sanctions.

${ }^{21}$ See, e.g., Emons (1994) for a detailed discussion of individual rationality.

22 Recall that under our rule the witness reports truthfully all signals. See Holmström and Myerson (1983) for a definition of the ex ante, interim, and ex post concepts.
} 
court. ${ }^{23}$ She will do so voluntarily because her expected payoff from doing so is nonnegative. Ex post, however, when the testimony has actually turned out to be wrong and the witness is sanctioned, she may end up with a negative payoff as can be seen by our example. We may, therefore, conclude that from an interim point of view it is individually rational to testify in court although ex post the witness may regret to have done so.

Let us conclude this section by showing that truth-revelation is impossible when the wage is decreasing in the precision such that, e.g., $w(b, l)>w(b, h)$, meaning the defendant prefers bad news with low rather than with high precision.

Proposition 4: If $w(b, l)>w(b, h)$ and/or $w(a, l)>w(a, h)$, no perfect truth-revealing mechanism with $S(X, y, p) \geq 0$ if $X \neq y$ and $S(X, y, p)=0$ if $X=y$ exists.

If the wage increases when the reported precision decreases, the probability that triggers the sanction if the witness is misleading decreases with the wage. But then it is impossible that the expected sanction increases with the wage as is necessary for truthtelling.

The non-existence problem arises because we sanction the witness if and only if testimony is wrong. The probability of a wrong testimony is lower for the high than for the low precision signal. To provide proper incentives, however, the expected sanction for wrong testimony must be higher for the high rather than the low precision signal.

The non-existence phenomenon disappears if we also allow the witness to be sanctioned when the testimony is right, i.e., if we let $S(X, y, p)>0$ for $X=y$. This can be seen by the following extension of our mechanism. Consider the case where $w(a, h) \geq w(a, l) \geq w(b, l)>w(b, h)$. We introduce sanctions $\sigma(y, p)$ which are levied in addition to $S(X, y, p)$. We charge the witness $\sigma(y, p)$ simply for reporting $(y, p)$, independently of whether this report turns out to be right or wrong. Let $\sigma(a, h)=\sigma(a, l)=\sigma(b, h)=0$ and $\sigma(b, l)=w(b, l)-w(b, h)$. Then the witness's wage

\footnotetext{
${ }^{23}$ For a neutral, disinterested witness all perfect truth-revealing sanctions are zero so that individual rationality is trivially satisfied.
} 
net of $\sigma, \quad W:=w-\sigma, \quad$ satisfies $W(a, h) \geq W(a, l) \geq W(b, h)=W(b, l)$. Construct $S^{*}(X, y, p)$ as given in Proposition 2, using $W$ rather than $w$. Obviously, the extended mechanism $\left(\sigma(\cdot) ; S^{*}(\cdot)\right)$ is perfect truth-revealing. ${ }^{24}$

If we sanction the witness only for wrong testimony, we do not have enough leverage to induce the report $(b, h)$ rather than $(b, l)$. Letting the witness pay $\sigma(b, l)>0$ gives us this leverage (alternatively, we can also reward the witness with $\sigma(b, h)<0) .{ }^{25}$ We plan to explore this case further in a subsequent paper.

\section{The Perjury Rule}

Let us now compare our truth-revealing mechanism $S^{*}$ with the perjury rule. As in our mechanism under a perjury rule the sanction is zero whenever the testimony is right. If, however, the testimony is wrong, the court uses this information to compute the probability $\phi$ that the witness did not tell the truth. If this probability exceeds a legal standard $\bar{\phi}$, the court imposes a sanction $s>0$; if the probability $\phi$ is below the legal standard, the sanction is zero. ${ }^{26}$ Formally,

$$
S_{p}(X, y, p)= \begin{cases}s, & \text { if } \phi(X, y, p) \geq \bar{\phi} ; \\ 0, & \text { otherwise. }\end{cases}
$$

Computing the probability $\phi$ of not having reported the truth turns out to be tricky. First, the court has to know the probabilities $\operatorname{Prob}(B)$ and $\operatorname{Prob}(A)$ with which the two states of nature occur. Note that we did not use this piece of information for our mechanism $S^{*}$. Moreover, the court needs to know the probability distribution over the signals $(Y, P)$ which we denote by $\operatorname{Prob}((Y, P)) .{ }^{27}$ To have some structure, assume that the

\footnotetext{
${ }^{24}$ Even more to the point is the mechanism $\sigma(y, p)=w(y, p) \forall(y, p)$ and no further sanctions for wrong testimony. Under this mechanism the witness's payoff equals zero for all reports.

${ }^{25}$ It is, of course, harder to satisfy individual rationality with mechanisms sanctioning correct testimony.

${ }^{26}$ For $\bar{\phi} \in(0,1)$ the perjury rule, essentially, works like a negligence rule with a "due care standard" $\bar{\phi}$. If $\bar{\phi}=0$, the perjury rule functions like a rule of strict liability and if $\bar{\phi}=1$ like a rule of no liability.

${ }^{27}$ This probability distribution depends of course on the stochastic process generating the outcomes $A$ and $B$. For an application see the following discussion of our dice example.
} 
low precision signals are at least as likely as the high precision signals, i.e., $\operatorname{Prob}((B, H)) \leq \operatorname{Prob}((B, L))$ and $\operatorname{Prob}((A, H)) \leq \operatorname{Prob}((A, L))$. Note once again that for our mechanism $S^{*}$ we did not use the probability distribution $\operatorname{Prob}((Y, P))$.

If the witness has reported, say, $(a, h)$ and nature has chosen $B$, the probability of not having told the truth is ${ }^{28}$

$$
\begin{aligned}
& \phi(B, a, h)= 1-\operatorname{Prob}((A, H) \mid B)=1-\frac{\operatorname{Prob}(B \cap(A, H))}{\operatorname{Prob}(B)}= \\
& 1-\frac{\operatorname{Prob}(B \mid(A, H)) \operatorname{Prob}((A, H))}{\operatorname{Prob}(B)}=1-\frac{(1-H) \operatorname{Prob}((A, H))}{\operatorname{Prob}(B)} .
\end{aligned}
$$

The probability that $(a, h)$ was not the true signal given $B$ equals the sum of the probabilities that the witness has observed $(a, l),(b, l)$, and $(b, h)$ given $B$ which in turn equals 1 minus the probability that $(a, h)$ was the true signal given $B$. Analogously, we compute

$$
\begin{aligned}
& \phi(B, a, l)=1-\frac{(1-L) \operatorname{Prob}((A, L))}{\operatorname{Prob}(B)}, \phi(A, b, h)=1-\frac{(1-H) \operatorname{Prob}((B, H))}{\operatorname{Prob}(A)}, \text { and } \\
& \phi(A, b, l)=1-\frac{(1-L) \operatorname{Prob}((B, L))}{\operatorname{Prob}(A)} .
\end{aligned}
$$

Let us illustrate these probabilities by means of our dice example. Before the dice are tossed, nature chooses with equal probability $1 / 2$ whether the witness will observe high or low precision signals. If she is to observe a low precision signal and the outcome of the first toss is 4 or 5 , she receives the signal $(A, L)$ and $(B, L)$ with equal probability 1/2. With this signal generating process we have $\operatorname{Prob}((A, H))=\operatorname{Prob}((A, L))=1 / 6$ and $\operatorname{Prob}((B, H))=\operatorname{Prob}((B, L))=1 /$. We then compute $\phi(B, a, h)=13 / 14, \phi(B, a, l)=$ $19 / 21, \phi(A, b, h)=4 / 5$, and $\phi(A, b, l)=11 / 15$.

Given these four probabilities of not having told the truth, we may now state the result that a neutral witness's testimony is misleading under the perjury rule when she has observed a high precision signal.

\footnotetext{
${ }^{28} \mathrm{~A}$ more precise yet more cumbersome notation for $\phi(B, a, h)$ would be $\phi(\neg(a, h) \mid B)$.
} 
Proposition 5: Under the perjury rule for a neutral witness the low precision signal weakly dominates the corresponding high precision signal.

This result is easily explained. Suppose the witness has observed the signal $(A, H)$ and she compares the honest and candid message $(a, h)$ with the honest but misleading message $(a, l)$. The probability that the testimony is wrong - the outcome which may trigger the perjury rule's sanction - is the same for both messages. Nevertheless, the probability of not having told the truth is higher for $(a, h)$ than for $(a, l)$, i.e., $\phi(B, a, h)>$ $\phi(B, a, l)$. Consequently, the expected sanction for $(a, h)$ is at least as great as for $(a, l)$ and reporting $(a, l)$ weakly dominates $(a, h)$ : If $\phi(B, a, h)<\bar{\phi}[\bar{\phi}<\phi(B, a, l)]$ so that the witness is never [always] sanctioned, misleading does not hurt. If, in contrast, $\phi(B, a, l)<$ $\bar{\phi}<\phi(B, a, h)$, being disingenuous is strictly better than being candid. ${ }^{29}$

Given that a neutral witness is misleading for high precision signals, the next natural question to ask is: under what conditions is her testimony under a perjury rule at least honest? Here we have the following straightforward result.

Proposition 6: If $\max [\phi(A, b, l), \phi(B, a, l)]<\bar{\phi} \quad$ or $\min [\phi(A, b, l), \phi(B, a, l)] \geq \bar{\phi}$, the neutral witness' testimony is honest.

From Proposition 5 we know that the witness always reports a low precision signal. If the probabilities of untruthful testimony are below the legal standard for both relevant messages $(b, l)$ and $(a, l)$, the witness is never sanctioned and, accordingly, indifferent between the two messages. Therefore, her report is honest (though not necessarily candid). If both probabilities of being untruthful are above the legal standard, for both messages the witness is sanctioned by the amount $s$ whenever the testimony is wrong. If the victim reports honestly, the probability of being wrong (1-H resp. $1-L)$, is lower than for an dishonest report ( $H$ resp. $L)$.

Let us finally analyze the incentives a perjury rule gives an interested witness. As can be expected, the result is negative. 
Proposition 7: If the witness is interested, a perjury rule is never truth-revealing.

Incentive compatibility requires for an interested witness that the sanctions increase with the strength of the testimony. To compensate for the increasing wage, the increase in the sanctions has to take on more values than the perjury rule does where the sanction is either 0 or $s$. To put it differently: the binary perjury rule lacks the sophistication to give an interested witness proper incentives.

Let us conclude this section with a discussion of the informational requirements of our sanction system $S^{*}$ and the perjury rule $S_{p}$. Our mechanism focuses essentially on the witness's wage schedule and uses this information to derive the incentive compatible sanctions. The perjury rule, in contrast, focuses on the stochastic processes generating the signals and the final outcomes to determine the probability that the witness did not tell the truth. Accordingly, both mechanisms use different pieces of information.

\section{Conclusions}

Economists have devoted much effort to developing truth-revealing mechanisms, but these developments have not been applied to courts. ${ }^{30}$ We have shown for a simple framework that existing legal practices create incentives for witnesses to give slanted or false testimony. More importantly, we have developed a mechanism that prevents slanted or false testimony.

A few qualifications are in order. First, we have looked at the incentive problem of preventing slanted and false testimony. There are of course other incentive problems playing an important role such as, e.g., withholding unfavorable information. Second, we did not worry about the witness's effort to gather the information. The more effort a witness provides, the more precise her signal, say. If effort were observable, the court could use this information to infer the quality of the testimony. Third, the process generating the evidence confirming or disconfirming the testimony is exogenous in our

\footnotetext{
${ }^{29}$ See, e.g., Kreps (1990), pp. 418-421, for a discussion of the pro and cons of the concept of weak dominance.

${ }^{30}$ Exceptions are Bernardo, Talley, and Welch (1999) and Sanchirico (1997).
} 
set-up. Endogenizing this process, as well the other two qualifications, seem interesting tasks for future research.

Many obstacles impede institutionalizing our mechanism, but a move to strict liability has the promise of significantly improving the quality of testimony in court. Moreover, it should economize significantly on transaction costs. 


\section{Appendix}

\section{Proof of Proposition 1:}

The result follows immediately from (1) - (6).

Q.E.D.

\section{Proof of Proposition 2:}

We use the first inequalities (1a)-(6a) to determine the smallest incentive compatible sanctions. Proposition 1 implies that we can set $S^{*}(A, b, l)=0$. (3a) then implies $S^{*}(B, a, l)=(w(a, l)-w(b, l)) / L$. (2a) then defines $S^{1}(A, b, h)=(w(b, h)-w(b, l)) /(1-L)$ while (6a) defines $S^{2}(A, b, h)=\frac{1}{L}\left[w(b, h)-w(a, l)+\frac{1-L}{L}(w(a, l)-w(b, l))\right]$. Here we have $S^{1}(A, b, h) \geq S^{2}(A, b, h) \quad \Leftrightarrow \quad[w(b, h)-w(b, l)]\left[\frac{L}{1-L}-1\right] \geq[w(a, l)-w(b, l)]\left[\frac{1-L}{L}-1\right]$ which holds because $L>1 / 2$. Hence, $S^{*}(A, b, h)=S^{1}(A, b, h)$.

Given this (1a) then defines $S^{1}(B, a, h)=\frac{w(a, h)-w(a, l)}{1-L}+\frac{w(a, l)-w(b, l)}{L}$, (5a) implies $S^{2}(B, a, h)=\frac{w(a, h)-w(b, l)}{L}$, and $(4 a)$ defines $\mathrm{S}^{3}(B, a, h)=$ $\frac{w(a, h)-w(b, h)}{H}+\frac{1-H}{H} \frac{w(b, h)-w(b, l)}{1-L}$. While it is straightforward to see that $S^{1}(B, a, h) \geq S^{2}(B, a, h)$, proving the second inequality is more tricky. Here we have $S^{1}(B, a, h) \geq S^{3}(B, a, h) \Leftrightarrow w(a, h)\left[\frac{H}{1-L}-1\right]+w(b, h)\left[1-\frac{1-H}{1-L}\right] \geq$ $w(a, l)\left[\frac{H}{1-L}-\frac{H}{L}\right]+w(b, l)\left[\frac{H}{L}-\frac{1-H}{1-L}\right]=$ $w(a, l)\left[\frac{H}{1-L}-1\right]+w(b, l)\left[1-\frac{1-H}{1-L}\right]+\left[\frac{H}{L}-1\right](w(b, l)-w(a, l)) \quad$ which holds given $H>L$ and our assumptions on $w(\cdot)$. Consequently, $S(B, a, h)=\frac{w(g, h)-w(a, l)}{1-L}+\frac{w(a, l)-w(b, l)}{L}$. 
It remains to be shown that (1b) --- (6b) also hold. (1b), (2b), and (3b) are obvious.

Substracting (3b) from (2b) yields $w(b, h)-w(a, l) \geq(1-H) S(A, b, h)-(1-L) S(B, a, l) \geq(1-H)$ $S(A, b, h)-H S(B, a, l)$, implying (6b). Adding (1b) to (3b) generates $w(a, h)-w(b, l) \geq(1-H)$ $S(B, a, h)+(H-L) S(B, a, l)>(1-H) S(B, a, h)-H S(B, a, l)$, meaning $(5 b)$ is satisfied. Last but not least, subtracting (2b) from (5b) yields $w(a, h)-w(b, h) \geq(1-H) S(B, a, h)-(1-H) S(A, b, h)$ $\geq(1-H) S(B, a, h)-H S(A, b, h)$ which is (4b).

Q.E.D.

\section{Proof of Proposition 3:}

If $Y=(B, L), w(b, l)-(1-L) S(A, b, l)=w(b, l) \geq 0$. If $Y=(B, H), w(b, h)-(1-H) S(A, b, h)=$ $w(b, h)-\frac{1-H}{1-L} w(b, h)+\frac{1-H}{1-L} w(b, l) \geq 0$ since $H>L$. If $Y=(A, L), w(a, l)-(1-L) S(B, a, l)=$ $w(a, l)\left[1-\frac{1-L}{L}\right]+\frac{1-L}{L} w(b, l) \geq 0 \quad$ as $\quad L \geq 1 / 2 . \quad$ Finally, if $Y=(A, H), \quad w(a, h)-(1-$ $H) S(B, a, h)=w(a, h)\left[1-\frac{1-H}{1-L}\right]+w(a, l)\left[\frac{1-H}{1-L}-\frac{1-H}{L}\right]+\frac{1-H}{L} w(b, l) \geq 0$ because $H>L \geq 1 / 2$.

Q.E.D.

\section{Proof of Proposition 4:}

If the true state is, e.g., $(B, L)$, reporting $(b, l)$ must be better than $(b, h)$ meaning $w(b, l)-(1-L) S(A, b, l) \geq w(b, h)-(1-L) S(A, b, h)$. If the true state is $(B, H),(b, h)$ must be better than $(b, l)$ meaning $w(b, h)-(1-H) S(A, b, h) \geq w(b, l)-(1-H) S(A, b, l)$. Rearranging gives us $(1-H)[S(A, b, l)-S(A, b, h)]>w(b, l)-w(b, h)>(1-L)[S(A, b, l)-S(A, b, h)]$ which cannot hold since $[S(A, b, l)-S(A, b, h)]$ has to be positive and $(1-H)<(1-L)$. The same argument applies to the signal $(A, L)$.

Q.E.D. 


\section{Proof of Proposition 5:}

If the witness has observed the high precision signal $(B, H)$, the expected sanction equals $(1-H) S_{p}(A, b, h)$ if she is honest and candid and $(1-H) S_{p}(A, b, l)$ if she is honest but not candid. Since $\phi(A, b, h)>\phi(A, b, l)$, we have $S_{p}(A, b, h) \geq S_{p}(A, b, l)$. The same argument applies to the signal $(A, H)$.

Q.E.D.

\section{Proof of Proposition 6:}

Proposition 4 implies that the witness either reports $(b, l)$ or $(a, l)$. If $\min [\phi(A, b, l), \phi(B, a, l)] \geq \bar{\phi}$, the sanction is $s$ for both messages whenever the testimony turns out to be wrong. Suppose the witness has observed $(B, H)$. If she reports honestly (but not candidly) $(b, l)$, the expected sanction is $(1-H) s<H s$ which is the expected sanction when she reports $(a, l)$. The same reasoning applies to the other three signals.

If $\max [\phi(A, b, l) ; \phi(B, a, l)]<\bar{\phi}$, the expected sanction is zero for both, $(a, l)$ and $(b, l)$. Accordingly, the witness will provide an honest testimony.

Q.E.D.

\section{Proof of Proposition 7:}

(3a) implies that $S(B, a, l)$ and $S(A, b, l)$ cannot both be zero for an interested witness. This observation together with Proposition 1 means that for an interested witness incentive compatible sanctions have to take on at least three different values. The perjury rule $S_{p}$ takes on at most two values, 0 and $s$.

Q.E.D. 


\section{References}

Bernardo, A., E. Talley, And I. Welch: A Theory of Legal Presumptions, University of Southern California Law School Working Paper No. 99-8 (1999), http://papers.ssrn.com/paper.taf?abstract_id=161189

COOTER, R. AND W. EMONS: Truth-Bonding and Other Truth-Revealing Mechanisms for Courts, University of Bern, Dept. of Econ. and U.C. Berkeley, School of Law Working Paper (2000), forthcoming.

Dewatripont, M. And J. Tirole: Advocates, Journal of Political Economy 107 (1999), 1-39.

EMOns, W. AND J. Sobel: On the Effectiveness of Liability Rules when Agents are not Identical, Review of Economic Studies, 58 (1991), 375-390.

EMOns, W.: The Provision of Environmental Protection Measures under Incomplete Information: An Introduction to the Theory of Mechanism Design, International Review of Law and Economics, 14 (1994), 479-491.

Grossman, S. AND O. HART: An Analysis of the Principal-Agent Problem, Econometrica, 51 (1983), 7-45.

Holmström, B. AND R. B. Myerson, Efficient and Durable Decision Rules with Incomplete Information, Econometrica, 51 (1983), 1799-1819.

KREPS, D.: A Course in Microeconomic Theory, Harvester Wheatsheaf, 1990.

MANDEL, M. J.: Going for the Gold: Economists as Expert Witnesses, Journal of Economic Perspectives 13 (1999),113-120.

MYERSON, R. B, Bayesian Equilibrium and Incentive-Compatibility: An Introduction, in Social Goals and Social Organization, Essays in Memory of Elisha A. Pazner, (L. Hurwicz, D. Schmeidler and H. Sonnenschein, Eds.), pp. 229 - 259, Cambridge: Cambridge University Press (1985).

Petzinger, T., Oil \& Honor : The Texaco-Pennzoil Wars, Beard Books, 1999.

Posner, R. A.: The Law and Economics of the Economic Expert Witness, Journal of Economic Perspectives 13 (1999), 91-99.

SANCHIRICO, C. W.: Enforcement by Hearing: An Integrated Model of Evidence Production, mimeo University of Virginia School of Law (1997), http://www.cstone.net/ csanchir/Evidence1.pdf

SHIN, H. S.: Adversarial and Inquisitorial Procedures in Arbitration, Rand Journal of Economics, 29 (1998), 378-405.

ThORnton, R. AND J. WARD: The Economist in Tort Litigation, Journal of Economic Perspectives 13 (1999), 101-112.

Usman, M.: The Endogenous Determination of Verifiability, mimeo Koç University, College of Administrative Sciences and Economics, Istanbul (1999). 
